\title{
Geneticists play the numbers game in vain
}

Helen Pearson, New York

The precise number of human genes might never be tallied, geneticists confessed this week, after handing out a cash prize for the nearest guestimate.

To non-geneticists at least, the admission may come as a surprise. Many had assumed that the human gene count was virtually settled at between 30,000 and 40,000, an estimate announced with great fanfare in February 2001 based on early analyses of the draft human genome sequence.

But two years on, geneticists who gathered at a Cold Spring Harbor Laboratory meeting in New York state acknowledged that they are no closer to a final tally. "I'd say we don't know the true gene number for any organism - and certainly not for humans," said bioinformatics expert Phil Green of the University of Washington, Seattle.

This uncertainty has now been highlighted by a sweepstake on the human gene tally, dubbed Genesweep. The rules of the wager, which was light-heartedly set up at a Cold Spring Harbor conference in 2000, stated that the winner would be announced this year. More than 460 bets have since been placed.

On 30 May, the winning estimate — the lowest one - was announced by organizer Ewan Birney of the European Bioinformatics Institute in Hinxton, UK. The prize goes to Lee Rowen, who directs a sequencing project at the Institute for Systems Biology in Seattle, Washington.

Rowen's wager of 25,947 is closest to the current reckoning of 24,847 made by the genetic database Ensembl. Like many good gamblers, she describes her number as "a stab"; one runner-up picked 27,462 because his date of birth was 27 April 1962.

The final gene tally is anyone's guess but it is unlikely to rise again to the estimates of 80,000-100,000 mooted a few years ago. Geneticists at the meeting came up with many reasons why genes - regions of DNA that code for proteins - have proved so difficult to identify.

One reason is that gene-predictor programs, which trawl through DNA for landmark sequences characteristic of a gene, are notoriously unreliable. For instance, they often erroneously pick up pseudogenes, copies of real genes that have become defunct.

Conversely, the programs can miss genes carrying variations in their landmark sequences - and are completely flummoxed by unconventional cases, such as tiny genes, overlapping genes or small genes hidden within larger ones. "No gene predictor will ever get these right," says fruitfly geneticist Gerald Rubin of the University of California, Berkeley.

Lines of back-up evidence that are commonly used to strengthen program

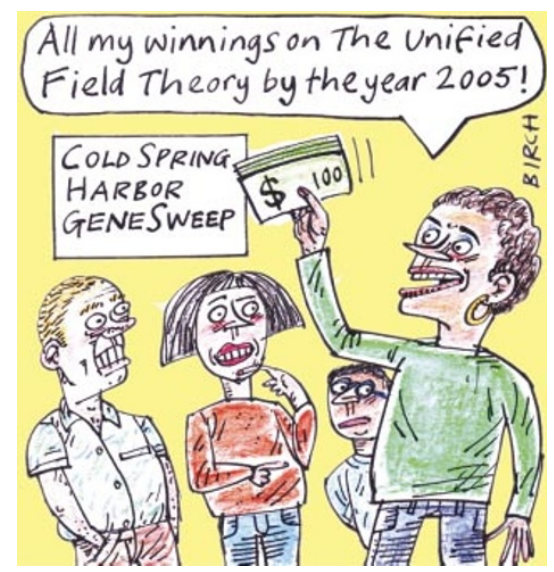

predictions are also fallible. For example, a putative human gene is considered more likely to be real if it matches a gene also found in databases of mouse, fruitfly or other organisms. But an unknown number of human genes have no obvious match.

With so many obstacles to tracking human genes, "there will never be a final number", predicts Jean Weissenbach, director of the sequencing centre Génoscope in Evry, France. Ultimately, it may turn out that every person has a different number of genes, as mutations have eliminated minor ones from their genome, he says.

www.ensembl.org/Genesweep

\section{Pet theory comes to the fore in fight against SARS}

\section{Alison Abbott}

The domestic cat is set to land a starring role in the future course of severe acute respiratory syndrome (SARS) — although it isn't yet clear whether it will be as saviour or scourge.

Experts have identified the cat as a potential animal model for SARS, but it may also fit the bill as a reservoir species for the SARS virus, guilty of bringing humans into contact with the disease.

Late last month, Chinese scientists

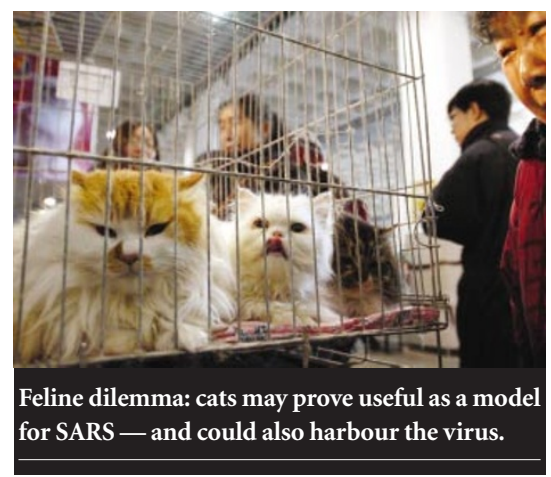

revealed that several species of wild animal on sale in the markets of southern China were harbouring a virus very similar to that believed to cause SARS (see Nature 423, 467; 2003). It is unclear whether these animals are a reservoir for the virus, or were infected by another species. And experts are now wondering whether a domestic animal may also be a reservoir species.

The only animal model available for SARS is the macaque monkey, which is expensive to use. Attempts to infect mice with the SARS virus have so far failed. But some pet cats in the Amoy Gardens apartment block in Hong Kong, where more than 100 residents contracted SARS in April (see Nature 423, 3-4; 2003), were found to harbour the virus, and to get sick from it.

"The cat may offer an alternative," says Albert Osterhaus, a virologist at Erasmus University in Rotterdam who developed the macaque model. Osterhaus has applied for ethical authorization to begin systematic studies on cats. Other laboratories, including the US Centers for Disease Control and Prevention in Atlanta, Georgia, are also assessing the cat's potential as an animal model.

If cats prove to be susceptible to infection, they could be responsible for bringing SARS into homes. The World Health Organization (WHO) is keen to define all possible reservoirs among species that come into regular direct contact with humans. It is establishing an international network of laboratories with expertise in zoonotic diseases - infections that jump between species - to address the problem.

Researchers at the National Microbiology Laboratory in Winnipeg, Canada, have already tested pigs and chickens and have found no evidence that they can be infected by the virus.

"We want to recruit more specialized labs around the world to help extend this type of work to all domestic species," says Klaus Stöhr, the WHO's chief SARS expert, based at the organization's Geneva headquarters. He warns that a domestic animal acting as a reservoir would pose a greater risk to humans than if only wild species harbour the virus. 